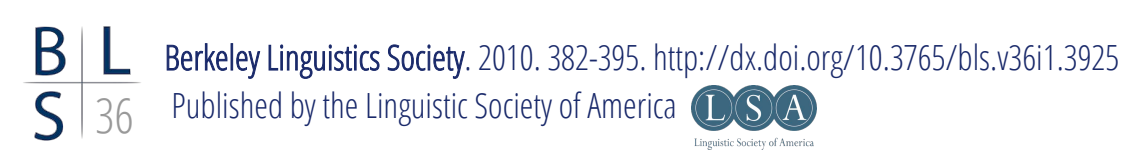

\title{
From Relativization to Nominalization and More: Evidence from the History of Okinawan
}

\author{
REIJIROU SHIBASAKI \\ Okinawa International University
}

\section{Introduction}

The nominalization-relativization syncretism is characteristic of languages in Tibeto-Burman areas (e.g. Noonan 1997; DeLancey 1999), whilst the diachronic process of the phenomenon is now pursued in East and Southeast Asian languages as well (e.g. Yap and Wrona forthcoming). These preceding works propose two different directions of change. One is that nominalization has developed into relativization (e.g. Yap and Matthews 2008) albeit with a lack of syntactic explicitness in some cases by the want of historical documents. The other concerns the inverse direction from relativization to nominalization, which is proposed by researchers such as LaPolla (2003 with Huang). Although they are opposing against each other, each survey result remains and raises an intriguing possibility, which is worth reconsideration through the analysis of other languages. However, it should be pointed out that preceding research cannot give a full account of the directions with a paucity of crucial historical evidence. Genetti (2008) embarks on a reconstructing research into the diachronic process in which relativization and nominalization each give rise to the other based on five Tibeto-Burman languages; she provides a good syntactic analysis, but any synchronic study seems to have its own limits. Building on these preceding works, this study addresses the historical development of the Okinawan nominalizer si, which used to be $s i$ (see the next section), out of its earlier usage as the head of relative clause i.e. from relativization to nominalization.

\section{$1 \quad$ Data}

Since the languages spoken in Okinawa have a history of about four-hundred years, it is possible to compare some sizeable materials at different synchronic 


\section{Reijirou Shibasaki}

stages for a historical-comparative study. This study thus examines as primary data several historical materials written in the sixteenth/seventeenth through eighteenth centuries; some other materials in later centuries are also used, albeit on an as-needed basis, as supplementary data sources. The materials are shown in (1).
(1) 16/17C: Omorosausi vols.1-22 (poems)
Early 18C: $\quad$ Gosamarutichiuchi (c. 1718) ${ }^{1}$
Shuusinkaneiri (c. 1718)
Mekarusi (c. 1718)
Unnamunukurui (c. 1718)
Timizinuyin (? 1733)
Late 18C: $\quad$ Hanauinuyin (after 1770)
19/20C: Ryuuka (traditional Okinawan verse songs)

According to Hokama (1995: 350) i.e. the unabridged dictionary of the Ancient Okinawan, sï can trace back to the oldest document Omorosausi, which had been complied in three parts from the sixteenth to seventeenth centuries. Omorosausi consists of twenty-two volumes of omoro i.e. songs as dedications to the gods and goddesses, and 1554 songs in total are included in the twenty-two volumes of sausi i.e. book or brochure. The oldest song is said to have been the omoro in the thirteenth century, while the latest is identified as the omoro sung by Queen Shoonei in the early seventeenth century (Hokama 2000b: 455). I used the Hokama's (2000b) edition of Omorosausi, referring to Shimizu (2004) if need be.

The materials in the eighteenth century all belong to the genre of kumiodori i.e. a traditional Okinawan musical drama. Kumiodori dramas utilize stories and themes with popular appeal, which are performed with traditional Okinawan songs and dances using stylized movements. The first four works in (1) were all written by Tamagusuku Chookun (1684-1734), the originator of kumiodori. The other two kumiodori texts are considered to have been written, respectively, in the mid and the latter half of the eighteenth century. Timizinuyin, which is usually known as the modern pronunciation Temizunoen, was written by Heshikiya Choobin (1700-1734) around 1733 (Ohtani 1981: 14). Hanauinuyin, usually known as Hanaurinoen, was made up by Takamiyagusuku Peechin (dates unknown); the text is generally believed to have been written sometime within two decades after 1770 (ibid.). All these texts of kumiodori are edited and included in Ifa (1962).

The phonetic form sï, albeit written $s u$ in the cursive form of kana, had been used from the sixteenth/seventeenth century to the late nineteenth century, specif-

\footnotetext{
${ }^{1}$ I referred to Okinawa Prefectural Board of Education (2000: 70) for the dates of the first four Kumiodori dramas. Ohtani (1981: 13) states that there is no conclusive evidence for the dates of Mekarusi and Unnamunukurui. Note that Gosamarutichiuchi is also known as Nidootichiuchi.
} 
ically until around 1870 i.e. the very early period in the Meiji Era [1868-1912] (Hokama 2000a: 308-310). In the early Meiji Era, the phonetic value of alveolar fricative [s] in $s u$ [si] remained to be used by members of the samurai class, while it has completed a phonetic change into the postalveolar fricative [j] in Present Day Okinawan (Hokama 1995: 759); the vowel quality is also changed from [i] to [i]. Yet for convenience sake, I will use the si form consistently in this study for clarity.

In the following sections, I will only illustrate some crucial examples excerpted from these data sources because of space limitations.

\section{Functional Changes of si}

\subsection{The Sixteenth/Seventeenth Century}

In Omorosausi, there are six examples of $s i$-headed clauses, and five of them can be translated as 'the one/person who does something...', while the other one is ambiguous in the interpretation. Since it might have served as a nominalizer (see below), I treat it as an example of nominalization. On the other hand, no example of the independent use of $s i$ was found in the texts. Let us take a look at some examples. ${ }^{2}$ Notice that elements in focus are all underlined.

(2) Omorosausi, vol. 3, $102(17 \mathrm{C})^{3}$

Ubudama ha

life-generating.ball TOP

inuru $\underline{\text { si }} \quad d u \quad$ yukakïru

bless si.person PT govern

'The person who (can) invoke(s) certain life-generating power from Ubudama (is the one/person who can) govern the world.'

(3) Omorosausi, vol. 17, 1187 (17C)

Chikwii ichigusiku

famous Ikei.castle

mira nu si ga hurubi,

see NEG si NOM perish

chikwii uni

famous spiritually.advanced.person

ncha $\quad$ si $\quad g a \quad$ masai...

see si NOM flourish

${ }^{2}$ For the transcription of Omorosausi I followed Shimizu (2004) unless otherwise noted.

3 The glossing conventions are as follows: COMP=complementizer; GEN=genitive; $\mathrm{HON}=$ honorific; LINK=clause-linker; $\mathrm{NEG}=$ negative; $\mathrm{NOM}=$ nominative; $\mathrm{NOML}=$ nominalizer; $\mathrm{NP}=$ noun phrase; $\mathrm{PT}=$ particle; $\mathrm{REL}=$ relativizer; $\mathrm{ST}=$ stance marker; $\mathrm{TOP}=$ topic; $\mathrm{v}=$ verb. 


\section{Reijirou Shibasaki}

'The one/person who does not see the famous Ikei Castle would perish, the one/person who sees spiritually advanced person would flourish...'

In (2) and (3), the meaning of si can be considered 'person', rendering the interpretation of 'the one/person who does something' as the head of the relative clause. While no independent use of $s i$ can be found in Omorosausi, there is still possibility that originally it was an independent nominal that indicates 'person'.

The following example may be ambiguous in the interpretation of si. Hokama's (2000b) edition of Omorosausi adds a footnote to this point that si serves as 'a person (that worships)', while Shimizu (2004) writes a note that si plays a role of nominalizer in this context. I interpret this particular case of $s i$ as an example of nominalization because unlike the other five examples, it exhibits increased polyfunctionality i.e. relativization and nominalization.

(4) Omorosausi, vol. 7, 389 (17C)

$\begin{array}{ll}\text { Chikwii } & \text { ajisuija } \\ \text { celebrated } & \text { king } \\ \text { shuyuimui } & \text { chuwariba, } \\ \text { Shuri.castle } & \text { be.HON } \\ \text { kiyun } & \text { achan } \\ \text { today.too } & \text { tomorrow.too } \\ \text { umichooyu } & \end{array}$

face

wugamu $\underline{s i} \quad g a \quad$ masai

worship si.person/NOML NOM surpass

'Since the famous King stays in Shuri Castle, the one/person who has the honor of meeting his face would flourish...' or '..., having the honor of meeting his face would be good...'

\subsection{The Early Eighteenth Century}

In the early eighteenth century, si began to be multifunctional whilst retaining both relativization and nominalization strategies. First, consider the following examples of relativization and nominalization, respectively, in (5) and (6).

(5) Shuusinkaneiri (18C)

Taru yu yubukasa nyi

who PT midnight PT

yadu kara ndi 'yu si $\underline{\text { s }} y a$ ?

lodging ask.for COMP say si.person PT

"Who is it that asks for lodging at this time of night?" (lit. "Who is the person that asks for...") 
(6) Mekarushi (18C)

\begin{tabular}{llllll} 
matsi & $n$ tamamizi & & & & \\
pine.tree & too waterfall too & & \\
waga & munu & tu & Pyu & \multicolumn{1}{l}{ si } & $y a$ \\
self.GEN & thing & COMP & say & si.NOML & PT \\
muri & ya $\quad$ Para & $n i$ & & \\
impossible & PT $\quad$ is & PT & &
\end{tabular}

'Saying that both pine trees and waterfalls are your own is unfair, isn't it?'

As to (5), Hokama (1976: 195) and Ifa (1962: 53) interpret the function of $s i$ as a nominalizer, providing the same note on this line. However, if we take it as a nominalizing function, the whole sentence turns out to be logically inconsistent, because 'the thing that asks for lodging' is logically impossible, whilst 'the person that asks for lodging' is semantically transparent. In (6), the functional role of $s i$ can be regarded as a nominalizer (see Hokama 1976: 231).

In addition to these functions, si came to have a new function at this stage, as follows.

(7) Shuusinkaneiri (18C)

\begin{tabular}{ll}
$\hat{\imath}$ gurisha & \multicolumn{1}{c}{ a siga } \\
say difficult & be \\
si.thing.NOM'but' \\
wan ya & Nakagusiku \\
I PT & place.name \\
Wakamatsi & $d u \quad$ yayuru. \\
person.name & PT be
\end{tabular}

"I hate to ask you, but I am Wakamatsu from Nakagusuku." (lit. "Thing that/what is difficult to say is I am Wakamatsu from Nakagusuku.")

(8) Mekarushi (18C)

kashiragi nu a siga

head.hair NOM be si.thing.NOM'but'

shija nu kami naran.

humans GEN hair be.not

"(The person i.e. Mekarushi) has a full head of hair, but (it) is not (like) humans." (lit. ?"Thing that there is a full head of hair is not the one of humans")

In (7) and (8), the nominalizer $s i$ is accompanied by the nominative marker $g a$, and the whole unit serves as a concessive conjunction 'although' (Ifa 1962: 276). Once we take it into account that the Japanese nominative case marker $g a$ underwent the similar functional extension from a nominative to a concessive conjunc- 


\section{Reijirou Shibasaki}

tion, this newly derived function would not be heterogeneous (see Genetti 1988 for similar issues in Newari, Tibeto-Burman languages). Kinjo (1974 [1944]) points out one construction Jiga (si + concessive conjunction) 'although' in Present Day Okinawan, albeit limited to the regional speech spoken in Naha. Considering both functional similarity and phonological change, the earlier form of Jiga i.e. siga may possibly have derived in the early eighteenth century.

\subsection{The Late Eighteenth Century}

In the latter half of the eighteenth century, the functional range of si had moved through the semantic bleaching of the original 'person' meaning. That is, the relativization strategy based on the lexical meaning 'the one/person who does something' faded out, while the nominalization strategy including the clausecombining function siga became dominant with progression of semantic bleaching. Here are examples of nominalization and concessive conjunction, respectively, in (9) and (10).

(9) Hanauinuyin (after 1770)

uchikurisha shusin

sorrow.suffer do.si.NOML.PT

tin $u$ usadami nu

heaven GEN fate GEN

kunu 'mmari tu muti...

this birth COMP think

'(I) think that lamenting and suffering (is due to) this life (of mine), a divine ordinance...

(10) Hanauinuyin (after 1770)

yuufukuna sudachi shichiwuta siga

rich upbringing do.PST si.thing.NOM'but'

dandan fushiyawashi tsizichi,

gradually unhappiness continue

Shuri nu simee naran...

place.name GEN living NEG.be

'(The person) was well-bred, but (now) is not living in Shuri because of adversities of life...'

\subsection{Interim Summary}

Table 1 summarizes the token frequency of the functions of si in the sixteenth through the late eighteenth centuries. The fourth function of si, i.e. stancemarking that is frequently used in later stages, has not yet appeared at these stages 
(see the next section; Shibasaki forthcoming). Figure 1 gives a graphic representation of the historical transition of $s i$ based on the proportional frequencies.

Table 1: The Token Frequency of the Functions of $s i$

\begin{tabular}{lccc}
\hline Function types & $16 / 17 \mathrm{C}$ & Early18C & Late18C \\
\hline si-relativization 'the one/person who...' & 5 & 3 & 0 \\
& $(83.3 \%)$ & $(15.8 \%)$ & \\
si-nominalization 'thing that...' & 1 & 9 & 4 \\
& $(16.7 \%)$ & $(47.4 \%)$ & $(36.4 \%)$ \\
si-marked clause linker 'although' & 0 & 7 & 7 \\
si-stance marker & 0 & $(36.8 \%)$ & $(63.6 \%)$ \\
\hline
\end{tabular}

Figure 1: The Proportional Frequency of the Functions of si

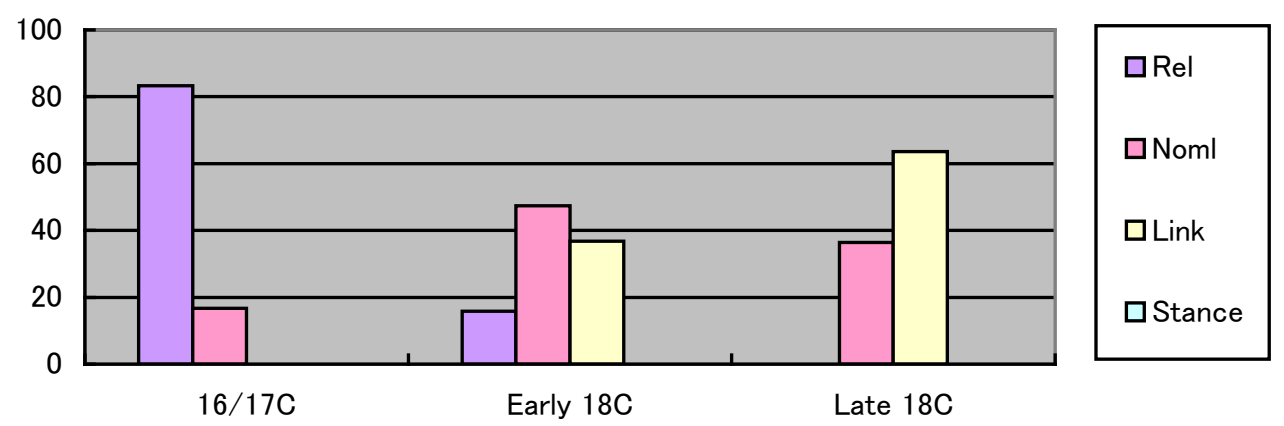

There are four important findings from this survey result. Firstly, the $s i$-headed relativization, which I translate as 'the one/person who does something,' declined in the early eighteenth century, subsequently disappearing in the late eighteenth century. Secondly, the clause-linking function 'although' newly emerged in the early eighteenth century. Thirdly, while the si-nominalization strategy was relatively infrequent in the sixteenth/seventeenth centuries, it became popular in the eighteenth century. Fourthly, the stance-marking strategy of si, which is dominant over the others in present-day Okinawan conversational discourse, had not yet developed at these stages. Of course, since these four findings are based only on the database in (1), especially those in the sixteenth/seventeenth and eighteenth centuries, I do not intend to generalize them beyond the realm of this case study. However, as discussed in the next section, the functional extension or functional transfer attested in the case of $s i$ is self-consistent or makes more sense to take it as a case of structural persistence, one of the robust tenets of grammaticalization (Hopper 1991). I will thus deal with the issue in the next section. 
Reijirou Shibasaki

\section{Mechanisms of Functional Change}

The erstwhile function of the $s i$-headed relativization developed into its newer nominalizing function as shown in the above. This functional transfer or expansion is confirmed at the clause-edge, which is quite suggestive of further grammaticalization from a morphosyntactic perspective. For example, in the history of Japanese i.e. the only language with which Okinawan is genetically affiliated, some case-marking particles e.g. the nominative $g a$ was developed into clausecombining particles. Furthermore, while other clause-combining particles such as kara 'because' and reba 'if' are used as part of subordinate clauses to introduce their main clauses, they often appear without main clauses, giving rise to clausefinal particles at the right periphery (see papers in Ohori 1998 and Higashiizumi 2006). Taking the morphosyntactic position of si into account, the nominalizing function of $s i$ has the potential to further develop its function to such stance marking functions as seen in the history of Japanese particles (see Yap, Matthews \& Horie 2004).

In this section, I will give a brief account of the mechanisms of the functional change of si, referring to both structural persistence and semantic bleaching. Yet before that, let us glance over how si had further expanded its function.

\subsection{Si as a Stance Marker}

Shinzato (2008: 13) states that "si never developed this sentence-final particle usage." If this is true, Okinawan has not yet proceeded enough to grammaticalize a nominalizer to a stance marker; otherwise, it might have followed a different pathway of change. Let us take a look at the following example.

(11) Punnabusi (19C?; Kadekaru 2003: 280) ${ }^{4}$

cizi $n u$ fe $n u$ tacu si

prohibition GEN board GEN stand si.exclamatory

kui sinubu madi nu cizi ya nesami

love remember even GEN prohibition PT be.not

'A prohibition order board is standing, (but it) would not forbid (us) to love' or 'A prohibition order board's standing would not (mean to) forbid (us) to love.'

In this example, si appears at the end of the first clause, rendering two types of

\footnotetext{
${ }^{4}$ When this song was written is not yet clear. According to Kadekaru (2003: 280), the name of Punnabushi was first found in the Anthology of Ryukyuuan Poems i.e. Ryuukadaizenshuu (1878) and that this song was one of those poems prevailing in the nineteenth century. I follow Kadekaru (2003), but see Hokama (1976: 111) for another possibility that this song dates back to the first half of the eighteenth century, although he mentions that the singer ?unnabushi's dates of birth and death are still unknown.
} 
interpretation as shown in the English translations. The first translation is based on the interpretation of $s i$ as a clause-final particle i.e. a stance marker. In other words, the clause followed by si turns out to be an independent clause. The second translation depends on the assumption that $s i$ serves to nominalize the preceding clause. That is, the $s i$-clause is the subject of the whole sentence. In fact, these two interpretations are suggested in the annotated bibliography for this poem in Hokama (1976: 115, nt.2). Considering the fact that this stance-marking function became much more popular in the next century, it would be a reasonable inference that due to the morphosyntactic ambiguity, si began to be used at the clausefinal position in the nineteenth century, taking on a poetic or an exclamatory function. $^{5}$

\subsection{Siga as a Stance Marker}

On the other hand, it is also pointed out in Section 2.2 that the siga 'although' lexicalization appeared in the early eighteenth century. Since the etymological meaning of $s i$ was 'person', it is no wonder that the semantically agent $s i$ frequently cooccurs with the nominative case marker $g a$. In fact, all the six examples of $s i$ in the head of relative clause in the sixteenth/seventeenth centuries were semantically agent, and five of the six appeared as siga. The other one is accompanied by the emphatic particle $d u$ i.e. sidu as in (2); however, even this si turns out to be agent in meaning. Notice that the nominative case marker ga cannot appear with the emphatic particle $d u$.

In the eighteenth century, siga was very frequently used especially when $s i$ served as a clause-combining function. In the early eighteenth century, for example, all the seven uses of the $s i$-marked clause linker 'although' in Table 1 were siga, while in the late eighteenth century, five of the seven si-marked clause linkers 'although' were siga. Therefore, it is reasonable to infer that the almost fixed expression siga linking particle may have functionally expanded into a stance marker in much the same way as si had developed it, as shown in the preceding section. Consider the example to follow.

\footnotetext{
${ }^{5}$ The clause-final particle usage of $s i$ came to indicate something 'deprecatory' or 'dismissive' in later stages, especially in conversational discourse by the young Okinawan people (Shibasaki forthcoming).
} 


\section{Reijirou Shibasaki}

(12) Mutudanabusi (Early 20C?; Shimabukuro and Onaga 1968: 103) ${ }^{6}$

$\begin{array}{llll}\text { Sinnikuihuni } & n u & \text { Picuru tuke jariba } \\ \text { dogout.canoe } & \text { NOM can.go } & \text { ocean } & \text { be.if }\end{array}$

kiju ya ?nzi 'ugasi Paca ja cusiga

today PT go meet tomorrow PT come.siga.ST

'(If my girlfriend lives within the) canoeing distance, (I can) go and meet

(her) and come (back) tomorrow, but (it's impossible).'

The clause-final siga in (12) can be considered to serve as a stance marker. The siga-clause conveys the poet's desire to see his girlfriend, while the unuttered main clause would convey his giving up of his desire to see her in the real world. Ahagon (1983: 226) lists both clause-final and clause-linking uses under the heading of siga, and regards the function of siga in (12) as a clause-final exclamatory use i.e. stance marker. In the twentieth century on, the stance-marking use has become the major function of si as well as siga (see Kinjo 1974: 101-102).

\subsection{Structural Persistence and Semantic Bleaching}

What is characteristic of the functional expansion of $s i$ is the structural persistence by which si is situated at a certain syntactic position. Take a look at Figure 2, which represents the schematized morphosyntactic structures of the four functions of si. Note that 'periods' means the stages in which functions in focus are mainly attested in the database.

Figure 2. The syntactic representations of the si-marked clause

\begin{tabular}{llll}
\hline Function types & Structures & Meanings & Periods \\
\hline$s i$-relativization & {$[[$ clause1...v $]+s i$ 'person'] NP... } & 'the one who...' & $16 / 17 \mathrm{C}$ \\
$s i$-nominalization & {$[[$ clause $1 . . \mathrm{v}]+s i$ 'thing'] NP... } & 'thing who...' & $17-18 \mathrm{C}$ \\
$s i$-marked clause linker & {$[[$ clause $1 . . . \mathrm{V}]+s i$ 'thing'] NP + ga, } & 'although... & $18 \mathrm{C} \sim$ \\
$s i$-stance marker & {$[$ clause $1 \ldots \mathrm{v}]+s i$} & 'speaker's stance' & $19 \mathrm{C} \sim$ \\
& {$[$ clause $1 . . . \mathrm{V}]+s i g a$} & 'speaker's stance' & $19 \mathrm{C} \sim$ \\
\hline
\end{tabular}

The verb form in the clause is attributive that modifies si, regardless of whether $s i$ is semantically 'person' or 'thing'; even after si changed into the clause-final stance marker, the verb form remains the same. In the earlier relativization and nominalization functions, si-marked clauses are embedded in the larger clauses, while the clause-linking function of the $s i$-marked subordinate clause calls for the

\footnotetext{
${ }^{6}$ Satoshi Nishioka states that the poem may have been sung by a man born in the Meiji Era [18681912] judging from the transcribed pronunciation.
} 
following main clause. Both si-marked and siga-marked stance marking clauses requires no clauses to follow. However, the point is that the $s i$-marked clauses have one syntactic structure in common i.e. [clause 1] + si/siga. What differentiates these functions from each other is the semantic content of $s i$. In other words, the $s i$-headed clause is used as a relative clause as long as $s i$ remains to indicate 'person', while the clause is used as a nominalized clause once si becomes semantically bleached. When the semantic content becomes empty, si comes to serve as a clause-final stance marker. Since the semantic bleaching proceeds in chronological order, it can be concluded that the functional transfer or expansion of si due to semantic bleaching and structural persistence. And this conclusion dovetails with Hopper's (1991) principle in (13).

(13) Principle of Persistence (Hopper 1991: 22)

"when a form undergoes grammaticalization from a lexical to a grammatical function, so long as it is grammatically viable some traces of its original lexical meanings tend to adhere to it, and details of its lexical history may be reflected in constraints on its grammatical distribution."

\section{Nominalization-Relativization Syncretism Revisited}

Finally, I would like to rethink what-is-called nominalization-relativization syncretism addressed at the beginning of this study. Issues on the nominalizationrelativization syncretism have been at the center of a linguistic controversy since Matisoff (1972). The two directions of change dead against each other have been proposed, for example, by Noonan (1997) and DeLancey (1999) on the one hand and by LaPolla (2003 with Huang) on the other. These two opposing ideas are nicely summarized in Genetti (2008). However, the languages surveyed in these preceding works are not always abundant in historical materials, but rather little or almost none, in comparison to languages relatively rich in historical documents such as Japanese and Okinawan. In this study, I thus examined the history of Okinawan, and found that the direction of change is from relativization to nominalization. Furthermore, this directional pathway is consistent with Principle of Persistence, a principle of grammaticalization in Hopper (1991). I will thus suggest that one linguistic phenomenon that is considered to be area-specific may be solved once we put it in a wider range of languages.

\section{References}

Ahagon, C. 1983. Ryuuka Kogo Jiten (The Dictionary of the Ancient Words in Ryuuka). Naha: Naha shuppan. 


\section{Reijirou Shibasaki}

DeLancey, S. 1999. Relativization in Tibetan. In Yogendra P. Yadava and Warren W. Glover, eds., Topics in Nepalese Linguistics, 231-249. Kamaladi, Kathmandu, Nepal: Rpyal Nepal Academy.

Genetti, C. 1988. A Syntactic Correlate of Topicality in Newari Narrative. In J. Haiman and S. A. Thompson, eds., Clause Combining in Grammar and Discourse, 29-48. Amsterdam: John Benjamins.

Genetti, C. 2008. Syntactic Aspects of Nominalization in Five Tibeto-Burman Languages of the Himalayan Area. Ms. UCSB (co-authored with Ellen Bartee A.R. Coupe Kristine Hildebrandt You-Jing Lin).

Higashiizumi, Y. 2006. From a Subordinate Clause to an Independent Clause. Tokyo: Hituzi Syobo Publishing.

Hokama, S. ed. 1976. Nantoobungaku (Literature in the South Island). Tokyo: Kadowaka-shoten.

Hokama, S. ed. 1995. Okinawa Kogo Daijiten (The Dictionary of the Ancient Okinawan Words). Tokyo: Kadokawa Shoten.

Hokama, S. 2000a. Okinawa no Kotoba to Rekisi (Okinawan Languages and Cultures). Tokyo: Chūkōbunko.

Hokama, S. ed. 2000b. Omorosausi, 2 vols. Tokyo: Iwanami bunko.

Hopper, P. J. 1991. On some principles of grammaticalization. In E. C. Traugott and B. Heine, eds., Approaches to Grammaticalization, vol. 1, 17-35. Amsterdam: John Benjamins.

Ifa, F. 1962. Ifa Fuyu Senshuu Ge (The Anthology of Fuyu Ifa 3). Okinawa: Okinawa Times.

Kadekaru, C. 2003. Omoro to Ryuuka no Sekai (The World of Omoro and Ryuuka). Tokyo: Shinwa-sha.

Kinjo, C. 1974 [1944]. Kinjo Chooei Zenshu (Collected works of Chooei Kinjo). Naha: Okinawa Times.

LaPolla, R. J. with Chenglong Huang. 2003. A Grammar of Qiang with Annotated Texts and Glossary. Berlin: Mouton de Gruyter. 
Matisoff, J. A. 1972. Lahu nominalization, relativization, and genitivization. In John P. Kimball, ed., Syntax and Semantics vol. 1, 237-257. New York and London: Seminar Press.

Noonan, M. 1997. Versatile nominalizations. In Joan Bybee and John Haiman, eds., Essays on Language Function and Language Type: Dedicated to Talmy Givón, 373-394. Amsterdam: John Benjamins.

Okinawa Prefectural Board of Education, ed. 2000. The History and Culture of Okinawa. Okinawa: Sun Printing.

Ohori, T. ed. 1998. Studies in Japanese Grammaticalization. Tokyo: Kuroshio Publishers.

Ohtani, K. 1981. The Okinawan Kumiodori: An analysis of relationship of text, music and movement in selections from Nidoo Tekiuchi. Master thesis. University of Hawaii at Manoa.

Shibasaki, R. forthcoming. From Nominalizer to Stance Marker in the History of Okinawan. In M.-D. Dikken and W. McClure, eds., Japanese/Korean Linguistics 18. Stanford: CSLI Publications.

Shimabukuro, S. and T. Onaga, eds. 1968. Ryuukazenshuu. Tokyo: Musashinoshoin.

Shimizu, A. 2004. Hyooon Omorosausi Chuushaku, 3 vols. (An annotated edition of Omorosausi). Osaka: Izumi-shoin.

Shinzato, R. 2008. Nominalization in Okinawan: From a Diachronic and Comparative Perspective. Ms. Georgia Institute of Technology.

Yap, F. H. and S. Matthews. 2008. The Development of Nominalizers in East Asian and Tibeto-Burman Languages. In M. J. López-Couso and E. Seona, eds., Rethinking Grammaticalization: New Perspectives, 309-341. Amsterdam: John Benjamins.

Yap, F.-H. \& J. Wrona (eds.) forthcoming. Nominalization in Asian Languages: Diachronic and Typological Perspectives, Volume 2: East and Southeast Asian Languages. Amsterdam/Philadelphia: John Benjamins. 


\section{Reijirou Shibasaki}

Yap, H. H., Matthews, S. \& K. Horie. 2004. From Pronominalizer to Pragmatic Marker: Implications for Unidirectionality from a Cross-Linguistic Perspective. In O. Fischer, N. Muriel, and H. Perridon, eds., Up and Down the Cline - The Nature of Grammaticalization, 137-168. Amsterdam: John Benjamins.

Reijirou Shibasaki

Okinawa International University

Department of British and American Language and Culture

2-6-1 Ginowan

Ginowan Okinawa 901-2701

Japan

reijiro@okiu.ac.jp

abu_dida_loh@hotmail.co.jp 